\title{
Sensitivity of soil respiration to moisture and temperature
}

\author{
M. E. Guntiñas ${ }^{1}$, F. Gil-Sotres ${ }^{1}$, M. C. Leirós ${ }^{1}$, C. Trasar-Cepeda ${ }^{2 *}$ \\ ${ }^{1}$ Departamento de Edafología y Química Agrícola, Grupo de Evaluación de la Calidad del Suelo, Unidad Asociada CSIC, Facultad \\ de Farmacia, Universidad de Santiago de Compostela, E-15782 Santiago de Compostela, Spain. ${ }^{2}$ Departamento de Bioquímica del \\ Suelo, IIAG-CSIC, Apartado 122, E-15780 Santiago de Compostela, Spain. ${ }^{*}$ Corresponding author: ctrasar@iiag.csic.es
}

\begin{abstract}
The sensitivity of soil respiration to moisture and temperature was evaluated in three soils from the Atlantic temperate humid zone (Galicia, NW Spain) dedicated to different types of land use (forest, grassland and cropland). Samples of the soils were incubated in the laboratory for 42 days under different temperature $(10,15,20,25,30$, $\left.35^{\circ} \mathrm{C}\right)$ and moisture $\left(40,60,80,100 \%\right.$ of field capacity) conditions. Emission of $\mathrm{CO}_{2}$ from Grassland soil was higher than from the other soils. However, despite the different organic matter contents and biochemical activities in the three soils, temperature and moisture were the main factors affecting respiration. It was not possible to demonstrate the effect of soil use on the temperature sensitivity of organic matter mineralization. Sensitivity to temperature was accurately determined by $Q_{10}$ expressions, but some results indicate that for correct estimation of $Q_{10}$ in the incubation experiments, the $\mathrm{CO}_{2}$ emission data obtained during the first few days of incubation should be disregarded. Furthermore, the sensitivity of the soil organic matter to temperature was higher at low soil moisture contents. This finding was surprising as it is generally considered that temperature has a greater effect on respiration in nearly saturated soils than in drier soils.
\end{abstract}

Keywords: Climate change, soil respiration, soil temperature, soil moisture, soil use

\section{Introduction}

It is now accepted by the scientific community that the climate is changing and that part of this change must be attributed to human activities (IPCC WG1, 2007). Climate change is manifested by changes in temperature, precipitation and length of the seasons (Smith et al., 2008). These factors affect the biological activity of soil and therefore the emission of $\mathrm{CO}_{2}$, one of the gases that causes the greenhouse effect and therefore also contributes to climate change (Cox et al., 2000). The existence of this important feedback effect has prompted several studies of how climate change affects the kinetics of soil organic matter mineralization and the emission of $\mathrm{CO}_{2}$ from soils (e.g. Kirschbaum, 2000; Smith et al., 2008). Climate change modifies soil temperature and moisture regimes simultaneously, and although many studies have attempted to determine the effect of temperature or moisture on soil respiration, very few have attempted to explore the combined effects of both factors (Bowden et al., 1998; Davidson et al., 2006; Curiel-Yuste et al., 2007). 
However, information on this topic is so scarce that there appears to be a lack of knowledge of how soil moisture affects the temperature sensitivity of soil organic matter decomposition, as the relationships between moisture content and sensitivity are not consistent across different soils or types of soil use (Craine and Gelderman, 2011).

Incubation of soil under controlled conditions continues to be one of the most commonly used methods of studying the emission of $\mathrm{CO}_{2}$ from soils, despite criticisms of the method by different researchers. The problems associated with such studies are mainly due to the fact that the conditions that the soils are exposed to in the laboratory are very different from field conditions (Smith et al., 2008). Furthermore, some authors believe that long-term incubation experiments will lead to alterations in the quality of the soil organic matter and in the proportion of the different fractions originally present, so that the incubated soil will be very different from the field soil (Dalias et al., 2001; Chen et al., 2010). However, despite these problems, laboratory-based soil incubation studies are commonly used to investigate the effect of climate change on $\mathrm{CO}_{2}$ emissions from soils because they are simple, easily carried out, and provide the least biased estimates of temperature sensitivity (Kirschbaum, 2000). Nonetheless, it must be taken into account that the information obtained is restricted to a smaller fraction of the total soil organic matter than in longer term incubations and, therefore short-term incubations may not provide much information about the long-term turnover of soil organic matter.

In addition to climatic factors, the quality of soil organic matter should also affect the rate of decomposition. In soils formed under similar climates and from similar parent material, the quality of the organic matter depends on the vegetation cover and the type of use and management to which the land is subjected. Rey and Jarvis (2006) have shown that the sensitivity of soil respiration to temperature is different in soils under deciduous forest and in soils under evergreen forest, because of differences in the composition of the plant remains that reach the soil and the subsequent differences in the organic matter. If such differences are only caused by the species composition of the plant cover, then the organic matter in agricultural soils (grassland and arable), which receive different types of inputs than forest soils, will presumably respond very differently to climate change. In fact, recent estimates suggest that European forest soils will possibly act as net $\mathrm{CO}_{2}$ sinks in response to climate change (Kirkby et al., 2005), whereas agricultural soils will either not undergo any changes (Heidmann et al., 2002) or will loss organic matter (Sleutel et al., 2003) and will therefore emit $\mathrm{CO}_{2}$. In light of these differences, it is essential to determine how the organic matter in soils under different types of use, and presumably of different quality (Miralles et al., 2009), would react to variations in climatic parameters. Such knowledge could then be used to plan the best use of the soil in order to minimize $\mathrm{CO}_{2}$ emissions and favour increased $\mathrm{C}$ stocks in soils. Unfortunately, very few mechanistic models enable prediction of the effect of climate change on soils (Liski et al., 2005), and there are therefore many uncertainties as regards the usefulness of such predictions. Part of this problem is derived from the fact that most models include parameters that do not specifically apply to the type of soil under study (Foereid, 2007). Furthermore, it is not known whether the labile and recalcitrant fractions of organic matter (present in different proportions depending on soil use) respond equally to climate change. Some authors suggest that the pool of recalcitrant $\mathrm{C}$ is more sensitive to climate change than the pool of more labile organic matter (Leifeld and Fuhrer, 2005; Fierer et al., 2006), whereas others have not found any differences in the rate of decomposition of labile and recalcitrant organic matter (Fang et al., 2005; Rey and Jarvis, 2006) and yet others have reported that the recalcitrant carbon in soils is not sensitive to variations in temperature (Giardina and Ryan, 2000).

Although at present the climate in Galicia (NW Spain) is humid temperate, the region is expected to undergo significant climate change because of its geographical 
position (latitude close to $40^{\circ} \mathrm{N}$ ) (IPCC, 2007), where winter precipitations and mean temperatures throughout the year are expected to increase (de Castro et al., 2005). Moreover, although forest soils already account for $42 \%$ of the soil cover in the region, much of the forest land has been converted from agricultural land in recent years, in response to European agrarian and environmental policies (García and Pérez, 2001). It is not yet clear whether this change in land use has led to an increase in carbon stocks in soils and/or modified the carbon biogeochemical cycle. Attempts to estimate the effects of these changes in land use have highlighted the lack of basic reference data regarding soil responses, such as how the mineralization kinetics of soil organic matter are modified in soils under different types of use, in response to changes in climatic conditions.

In light of the predicted modifications in climate conditions and land use changes, in the present study we investigated the mineralization kinetics of organic matter in soils under different types of use and under diverse moisture and temperature conditions, with the aim of obtaining basic information about the following: a) the effects of modifications in temperature and moisture on $\mathrm{CO}_{2}$ emissions from soils, and b) the combined effects of both parameters. Moreover, and despite the fact that the study included only three soils, we also intended to determine the extent to which the type of land use modulates the effect of the changes in moisture and temperature on soil respiration. The study was based on the following underlying hypotheses: i) increases in soil moisture that do not involve anaerobiosis will increase the sensitivity of soil respiration to temperature, and ii) mineralization of organic matter in cultivated soils, which are usually treated with organic fertilizers, will differ from mineralization of organic matter in soils under natural forest vegetation, and will possibly be more sensitive to changes in moisture content and temperature.

\section{Material and Methods}

\subsection{Soils, soil sampling and soil preparation}

Three soils representative of different types of land use (forest, grassland and cropland) in Galicia were selected for study. The forest soil (Forest) is an Umbrisol (ISSS Working Group R.B., 1998) under Atlantic oak (Quercus robur L.), which is the climax vegetation in Galicia. The grassland soil (Grassland) is also an Umbrisol subjected to intensive grassland use and represents intensively managed grassland soils derived more than 40 years ago from former forest soils and fertilized intensively every year, mainly with cow slurry (200$250 \mathrm{~kg} \mathrm{~N} \mathrm{ha}^{-1}$ year $^{-1}$ ). In these grasslands the vegetation is dominated by Lolium multiflorum Lam. with a scarce presence of legumes, mainly Trifolium repens L. Finally, the cropland soil (Cropland) is a Regosol (ISSS Working Group R.B., 1998) derived from an Umbrisol, degraded due to continuous cultivation, and represents an agricultural soil; this type of soil is usually found in rural areas, close to houses, and is cultivated throughout the year by crop rotation (maize, Zea mays L.; rapes, Brassica napus L., and potatoes, Solanum tuberosum L., in a bi-annual crop succession) and with application of large amounts of both organic (manure) and inorganic (NPK) fertilizers (around $150 \mathrm{~kg}$ of $\mathrm{N} \mathrm{ha}^{-1}$ year $\left.^{-1}\right)$. The location and the main physical and chemical characteristics of each of the soils are shown in Table 1.

Soil sampling (0-10 cm, A horizon after litter and organic layer removal) was carried out after a period of more than 20 days without precipitation (so that the soils were as dry as possible and could be watered to obtain the different moisture contents required), and at least 1 month since the last agricultural treatments had been carried out in the Grassland and Cropland soils (grass cutting and maize collection, respectively). In the laboratory, the soils were sieved $(<4 \mathrm{~mm})$ to remove fragments of rock and minimize disruption of soil aggregates; the fine roots were removed (manually) and the soils were homogenized. The moisture content was determined by gravimetry in an aliquot of moist soil dried at $105^{\circ} \mathrm{C}$ for $24 \mathrm{~h}$. 
An aliquot of each soil was used to determine the water retained at $-33 \mathrm{kP}$ pressure (water field capacity, i.e. the moisture held after free drainage), with a tension plate apparatus (Guitián and Carballas, 1976). Another aliquot of each soil was air-dried and used for the general analyses outlined further below.

Table 1. Main characteristics and physical and chemical properties of the soils. For each property, different letters indicate that values in the different soils are significantly different $(p<0.01)$.

\begin{tabular}{|c|c|c|c|}
\hline & $\begin{array}{c}\text { Forest } \\
\text { (Umbrisol) }\end{array}$ & $\begin{array}{c}\text { Grassland } \\
\text { (Umbrisol) }\end{array}$ & $\begin{array}{l}\text { Cropland } \\
\text { (Regosol) }\end{array}$ \\
\hline \multicolumn{4}{|l|}{ Site characteristics } \\
\hline Soil parent material & Schists & Granodiorites & Granodiorites \\
\hline Longitude & $8^{\circ} 21^{\prime} 30^{\prime \prime} \mathrm{W}$ & $8^{\circ} 42^{\prime} 30^{\prime \prime} \mathrm{W}$ & $8^{\circ} 42^{\prime} 35^{\prime \prime} \mathrm{W}$ \\
\hline Latitude & $42^{\circ} 36^{\prime} 58^{\prime \prime} \mathrm{N}$ & $42^{\circ} 59^{\prime} 00^{\prime \prime} \mathrm{N}$ & $42^{\circ} 59^{\prime} 10^{\prime \prime} \mathrm{N}$ \\
\hline \multicolumn{4}{|c|}{ Main physical, chemical and biochemical soil properties } \\
\hline Soil texture & Sandy loam & Sandy loam & Sandy loam \\
\hline Field capacity ( $\mathrm{g} \mathrm{H}_{2} \mathrm{O} \mathrm{g}^{-1}$ soil) & $0.85 a$ & $0.60 b$ & $0.42 c$ \\
\hline Soil pH (in water) & $4.81 a$ & $5.43 b$ & $5.01 c$ \\
\hline Total C (\%) & $8.82 a$ & $8.26 a$ & $5.22 b$ \\
\hline Total N (\%) & $0.88 \mathrm{a}$ & $0.70 \mathrm{~b}$ & $0.47 \mathrm{c}$ \\
\hline $\mathrm{C} / \mathrm{N}$ & $10 a$ & $12 a$ & $11 a$ \\
\hline Permanganate-oxidizable $\mathrm{C}^{\bullet}$ & $7.00 a$ & $5.28 a$ & $5.77 a$ \\
\hline HWS carbohydrates & $2.30 a$ & $0.85 b$ & $1.25 c$ \\
\hline Dehydrogenase activity $^{*}$ & $0.53 a$ & $1.40 b$ & $0.38 c$ \\
\hline $\mathrm{CM}^{-C e l l u l a s e}$ activity $^{\#}$ & $0.36 a$ & $0.40 a$ & $0.12 b$ \\
\hline ß-glucosidase activity ${ }^{\&}$ & $2.14 a$ & $2.63 b$ & $1.21 c$ \\
\hline Invertase activity & $7.29 a$ & $8.22 b$ & $4.23 c$ \\
\hline
\end{tabular}

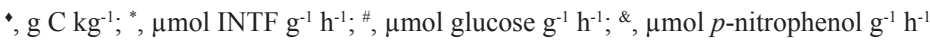




\subsection{Incubation procedure and soil analysis}

Aliquots of each soil (equivalent to $100 \mathrm{~g}$ of oven dry soil) were wetted with distilled water to obtain different moisture levels. In both soils, Forest and Grassland, 4 moisture levels (40, 60, 80 and 100\% field capacity) were considered (corresponding to 34, 51, 68 and $85 \mathrm{~g}$ $\mathrm{H}_{2} \mathrm{O} 100 \mathrm{~g}^{-1}$ soil for Forest and 24, 36, 48 and $60 \mathrm{~g} \mathrm{H}_{2} \mathrm{O}$ $100 \mathrm{~g}^{-1}$ soil for Grassland). In the third soil, Cropland, the moisture content at the time of sampling was already $60 \%$ of the field capacity, and therefore only three moisture contents were considered $(60,80$ and $100 \%$ field capacity, corresponding to 25,34 and $42 \mathrm{~g}$ $\mathrm{H}_{2} \mathrm{O} 100 \mathrm{~g}^{-1}$ soil, respectively). Once wetted, the soil samples (three replicate samples of each soil for each moisture level and for each temperature considered) were placed in plastic containers and maintained in hermetically sealed Mason jars $\left(2000 \mathrm{~cm}^{3}\right)$ for 42 days at temperatures of $10,15,20,25,30$ and $35^{\circ} \mathrm{C}$, respectively. These temperatures were selected in order to take into account the present range of temperature of the soils in the area, as well as higher temperatures that may be produced as a result of drastic climate change, and in the case of $35{ }^{\circ} \mathrm{C}$ to estimate the maximum possible effect of warming on soil metabolism (Cross and Grace, 2010). The soil containers were weighed every week and distilled water was sprayed evenly over the surface of the soils to compensate for any loss of water. A vial with $\mathrm{NaOH}$ was placed in each jar to capture the $\mathrm{CO}_{2}$ emitted. This vial was changed daily during the first ten days and then every 3-4 days, and the $\mathrm{NaOH}$ was replaced each time. The $\mathrm{CO}_{2}$ emitted was determined by titration of the remaining $\mathrm{NaOH}$ in the vials with an acid, after prior precipitation (with barium chloride) of the carbonates formed (Guitian and Carballas, 1976). The $\mathrm{CO}_{2}$ titrations were carried out in triplicate throughout the incubation, so that the individual value in each case is the mean value from 9 determinations.

Soil pH was determined in water (ratio 1:2.5), particle size distribution was determined by Robinson's pipette method, total carbon by a modification of Sauerland's method, and total nitrogen by Kjeldahl's method (Guitián and Carballas, 1976). Permanganate oxidizable carbon (permanganate oxidizable C) was determined according to Tirol-Padre and Ladha (2004). The hot water soluble carbohydrates $\left(80{ }^{\circ} \mathrm{C}, 16 \mathrm{~h}\right)$ (HWS carbohydrates) were determined by the anthrone method (Ceccanti et al., 1993). Soil enzymatic activities (dehydrogenase, CM-cellulase, ß-glucosidase and invertase activities) were determined following the methods described by Trasar-Cepeda et al. (2008).

\subsection{Mathematical models for studying the effect of temperature and moisture on soil respiration}

The following three equations were used to study the effect of temperature on soil respiration: 1) the constant emission model; 2) the one-compartment model, and 3) the two-compartment model. First of all, the temperature dependence was estimated by the rates measured for equal amounts of carbon emitted (constant emission model). For this, the cumulative total amount of carbon respired was determined for each soil at $10{ }^{\circ} \mathrm{C}$ and at the lowest moisture content (Rey and Jarvis, 2006). For the other temperatures and moisture levels, the number of days required to reach this amount of carbon respired was determined. For each soil and incubation condition, the mean rate of carbon mineralization was calculated by dividing the above-mentioned amount of mineralized carbon by the number of days required for its mineralization. The mean rates thus calculated were fitted to the following equation (1):

$$
\mathrm{C}_{\mathrm{m}}=\mathrm{C}_{\min } \mathrm{e}^{b \mathrm{~T}}
$$

where $\mathrm{C}_{\mathrm{m}}$ is the rate of carbon mineralization measured at temperature $\mathrm{T}\left(\mu \mathrm{g} \mathrm{CO}_{2}-\mathrm{C} \mathrm{g}^{-1}\right.$ initial $\left.\mathrm{C} \mathrm{day}^{-1}\right), \mathrm{C}_{\min }$ is the basal carbon mineralization rate at $0{ }^{\circ} \mathrm{C}, \mathrm{T}$ is the incubation temperature $\left({ }^{\circ} \mathrm{C}\right)$, and $b$ is a parameter related to the sensitivity of $\mathrm{C}_{\mathrm{m}}$ to temperature.

Likewise, for each soil, moisture level and incubation temperature, the mineralization data (expressed per unit 
of C initially present in the soil) were fitted to a firstorder one-compartment model (Stanford and Smith, 1972):

$$
\mathrm{C}_{\text {cum }}(\mathrm{t})=\mathrm{C}_{0}\left(1-\mathrm{e}^{-k 0 t)}\right.
$$

where $\mathrm{C}_{\text {cum }}(\mathrm{t})$ is the cumulative $\mathrm{C}$ mineralized (mg $\mathrm{CO}_{2}-\mathrm{C} \mathrm{g}^{-1}$ initial $\mathrm{C}$ ) until time $\mathrm{t}$ (days), $\mathrm{C}_{0}$ is the potentially mineralizable $\mathrm{C}\left(\mathrm{mg} \mathrm{CO}_{2}-\mathrm{C} \mathrm{g}^{-1}\right.$ initial C) and $k_{0}$ is the decomposition rate coefficient for mineralization of carbon $\left(\right.$ day $\left.^{-1}\right)$.

Finally, for each soil, moisture level and incubation temperature, the mineralization data were fitted to a first-order two-compartment model (Andrén and Paustian, 1987):

$$
\mathrm{C}_{\text {cum }}(\mathrm{t})=\mathrm{C}_{1}\left(1-\mathrm{e}-{ }^{k 1 t}\right)+\mathrm{C}_{2}\left(1-\mathrm{e}^{-} k^{2 t}\right)
$$

where $\mathrm{C}_{\text {cum }}(\mathrm{t})$ is the cumulative $\mathrm{C}$ mineralized (mg $\mathrm{C}-\mathrm{CO}_{2} \mathrm{~g}^{-1}$ initial C) until time $\mathrm{t}$ (days), $\mathrm{C}_{1}$ is the mass of organic labile $\mathrm{C}$ fraction $\left(\mathrm{mg} \mathrm{CO}_{2}-\mathrm{C} \mathrm{g}^{-1} \mathrm{C}\right), \mathrm{C}_{2}$ is the mass of the recalcitrant $\mathrm{C}$ fraction $\left(\mathrm{mg} \mathrm{CO}_{2}-\mathrm{C} \mathrm{g}^{-1}\right.$ C) and $k_{1}, k_{2}$ are the first-order kinetic decomposition rate coefficients for the first (labile) and second (recalcitrant) compartments, respectively $\left(\right.$ day $\left.^{-1}\right)$. In order to fit the model to the data, it was assumed that $\left(\mathrm{C}_{1}+\mathrm{C}_{2}\right)=1000 \mathrm{mg} \mathrm{C} \mathrm{g}^{-1}$ initial $\mathrm{C}$ (i.e. that the sum of the two pools is equal to the total amount of initial organic carbon in the sample).

For each soil and moisture level, the sensitivity of soil emission to temperature was determined from the $Q_{10}$ value, which was calculated using the following expression:

$$
Q_{10}=e^{(10 c)}
$$

where $c$ is the temperature coefficient $(b$ or $k$, depending on the equation used).

To study the effect of moisture (M, \% field capacity) on soil respiration, for each of the temperatures considered, the accumulated respiration values $\left(\mathrm{C}_{\text {cum }}\right.$, $\mathrm{mg} \mathrm{CO}_{2}-\mathrm{C}$ emitted per $\mathrm{g}$ of initial $\mathrm{C}$ ) after 10 and 42 days (chosen to represent, respectively, a mid-point and the end-points of the incubation period) were fitted to the following equations, chosen on the basis of their simplicity and their widespread use by different authors (Rodrigo et al., 1997; Curiel-Yuste et al., 2007, amongst others):

Linear

$$
\mathrm{C}_{\mathrm{cum}}=\alpha+q_{m} \mathrm{M}
$$

Semilogarithmic

$$
\mathrm{C}_{\text {cum }}=\alpha+q_{m} \log \mathrm{M}
$$

Partial parabolic

$$
\mathrm{C}_{\text {cum }}=\alpha+q_{m} \mathrm{M}^{2}
$$

Complete parabolic $\mathrm{C}_{\text {cum }}=\alpha+q_{m} \mathrm{M}+q_{m} \mathrm{M}^{2}$

where $\alpha$ represents the accumulated mineralization at $0 \%$ field capacity (or at $1 \%$ moisture content for the semilogarithmic equation), and $q_{m}$ and $q^{m}$ are the coefficients of dependency of soil respiration on moisture.

\subsection{Statistical analysis}

All data for the same soil and incubation condition were averaged to generate a mean value to avoid pseudo-replication (Mager, 2010). The Statistica 6.0 programme $\left(\mathrm{StatSoft}^{\mathbb{B}}\right)$ for Windows (StatSoft Inc. 2001) was used to calculate mean values and deviations, as well as to fit data to the different equations cited in the study and to apply Student's t tests to determine any significant differences in mean values for different soils.

\section{Results}

\subsection{General soil properties}

All three soils are acidic, although the Forest soil has the lowest $\mathrm{pH}$. The $\mathrm{C}$ content was similar in the Forest and Grassland soils and much higher than in the Cropland soil; the $\mathrm{C} / \mathrm{N}$ ratio was very similar in all three soils (Table 1). The kinetics of organic matter extraction with $33 \mathrm{mM}$ potassium permanganate 
indicate that the content of oxidizable $\mathrm{C}$ was initially highest in the Forest soil and lowest in the Grassland soil. A similar result was obtained for the hot water soluble carbohydrates (Table 1). The dehydrogenase activity was significantly higher in the Grassland soil than in the other two soils, indicating that the activity of the edaphic microbiota was higher in the Grassland soil than in the other soils. Moreover, the activities of the $\mathrm{C}$ cycle enzymes (CM-cellulase, $\beta$-glucosidase and invertase) were always higher in the Grassland soils than in the other two soils and the values were significantly lower in the Cropland soil than in the Forest and Grassland soils (Table 1).

\section{2. $\mathrm{CO}_{2}$ emission}

During the 42 days of the incubation period, the highest absolute emission was $1699 \mathrm{mg}$ of $\mathrm{CO}_{2}$ $100 \mathrm{~g}^{-1}$ of soil generated by the Grassland soil at $100 \%$ field capacity and $35{ }^{\circ} \mathrm{C}$. This quantity was respectively 367 and $1025 \mathrm{mg} 100 \mathrm{~g}^{-1}$ higher than the $\mathrm{CO}_{2}$ emitted by the Forest (maximum emission: $1332 \mathrm{mg}$ of $\mathrm{CO}_{2} 100 \mathrm{~g}^{-1}$ ) and Cropland soils (maximum emission: $676 \mathrm{mg}$ of $\mathrm{CO}_{2} 100 \mathrm{~g}^{-1}$ ) under the same incubation conditions (Figures $1,2)$. The organic matter in Grassland was the most susceptible to mineralization processes (maximum emission represents $5.61 \%$ of total C) and the organic matter in Cropland the least susceptible (maximum emission, $3.53 \%$ of total C). These results suggest that the lability of the soil organic matter (determined chemically) does not accurately reflect how the soil will respond when incubated under controlled conditions. On the contrary, the values of the soil biochemical properties related to the activity of the active microbiota (dehydrogenase) or to the capacity to hydrolyze carbonaceous compounds (CM-cellulase, $\beta$-glucosidase and invertase activities) appear to be better indicators of the mineralization capacity of the organic matter in incubation experiments.

Considering the absolute values of $\mathrm{CO}_{2}$ emission, the differences between soils were significant at $p<0.001$ (Figure 1 and Figure 2), whereas considering the total $\mathrm{C}$ expressed as percentages, the differences were only significant at $p<0.01$ (data not shown).

\subsection{Effect of temperature on $\mathrm{CO}_{2}$ emissions}

\subsubsection{Rates of mineralization for the same total amount of emitted carbon, constant emission model}

The lowest amounts of $\mathrm{CO}_{2}$ were emitted at the lowest temperatures and moisture contents throughout the incubation period. As the temperature and soil moisture increased, the number of days required to reach this amount decreased (Figures 1,2). This was most evident in the Grassland soil, in which at 100\% field capacity and $35^{\circ} \mathrm{C}$, only 1.1 days were required to produce the same amount of $\mathrm{CO}_{2}$ as produced in 42 days at $40 \%$ moisture content and $10{ }^{\circ} \mathrm{C}$. Under the same conditions $\left(35^{\circ} \mathrm{C}\right.$ and $100 \%$ field capacity) the Forest soil required 1.5 days to produce the amount emitted at the lowest moisture level and temperature, and the Cropland soil, 1.8 days. These differences between soils were significant $(p<0.01)$. Thus, this first estimation of the kinetics of the process indicated that the response of the soils to the incubation conditions was different, either reflecting different amounts of the most labile organic matter in each soil or different sensitivities of the organic matter and microorganisms to temperature

For all three soils and all moisture contents, the relationship between the rate of emission and temperature followed a van't Hoff type equation (equations 1 and 4), and the explained variance $\left(\mathrm{R}^{2}\right)$ was always higher than $90 \%$ (Table 2 ). The $Q_{10}$ values obtained for the Grasssland soil were generally lower than those obtained for the other soils, and (except at the lowest moisture content) were significantly different $(p<0.001)$ from those corresponding to the Forest and Cropland soils (Table 2). Moreover, it can be seen that for all three soils, $Q_{10}$ generally decreases with increasing moisture. 
FOREST SOIL

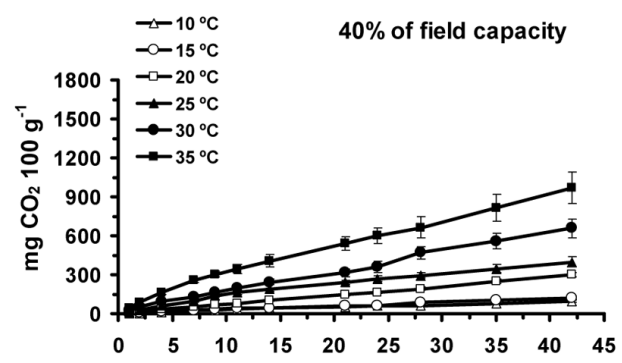

$60 \%$ of field capacity

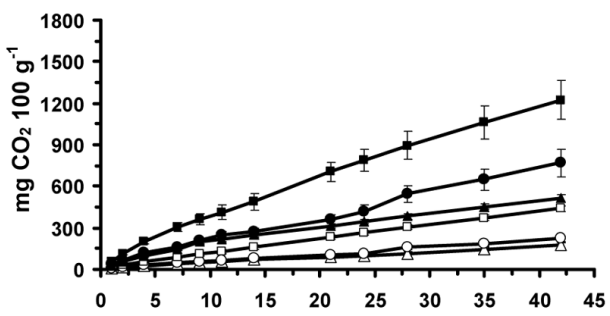

$80 \%$ of field capacity

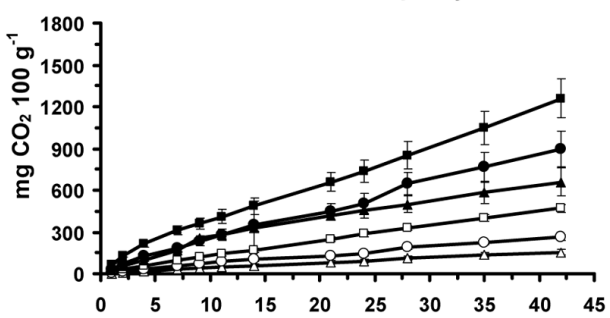

$100 \%$ of field capacity

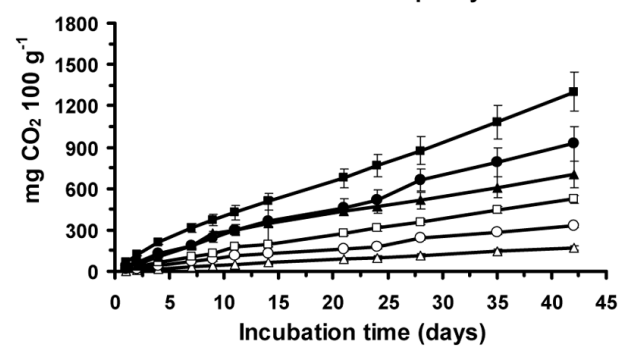

GRASSLAND SOIL

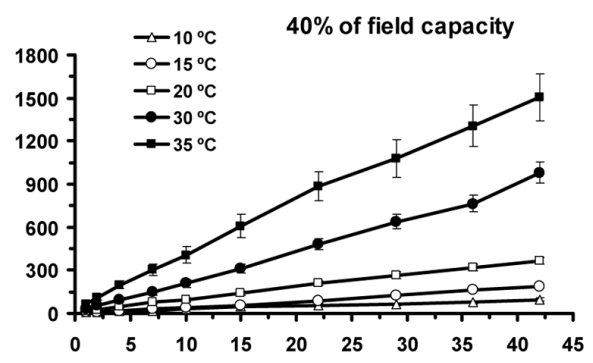

$60 \%$ of field capacity

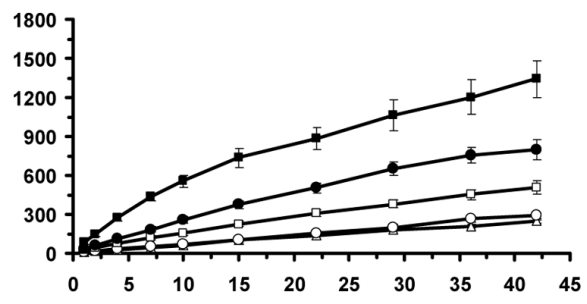

$80 \%$ of field capacity

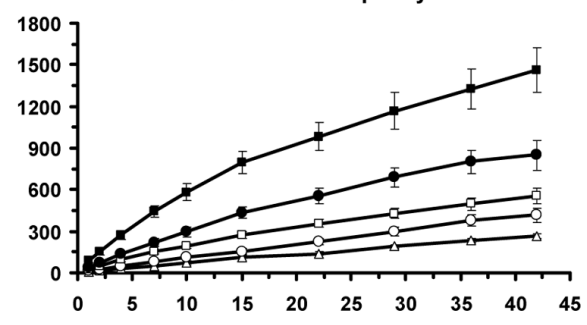

$100 \%$ of field capacity

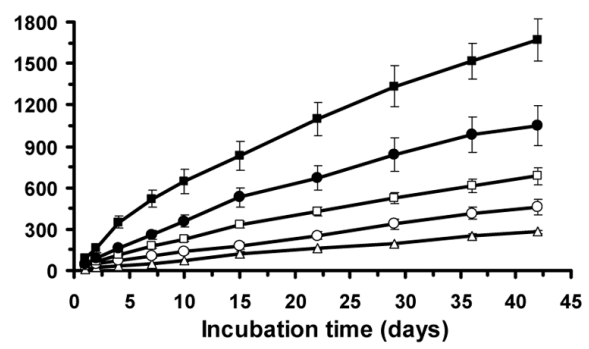

Figure1. Cumulative carbon mineralization values $\left(\mathrm{mg} \mathrm{CO}_{2} 100 \mathrm{~g}^{-1}\right)$ measured at different temperatures and moisture contents over the incubation period (42 days) for the Forest and Grassland soils 


\section{CROPLAND SOIL}

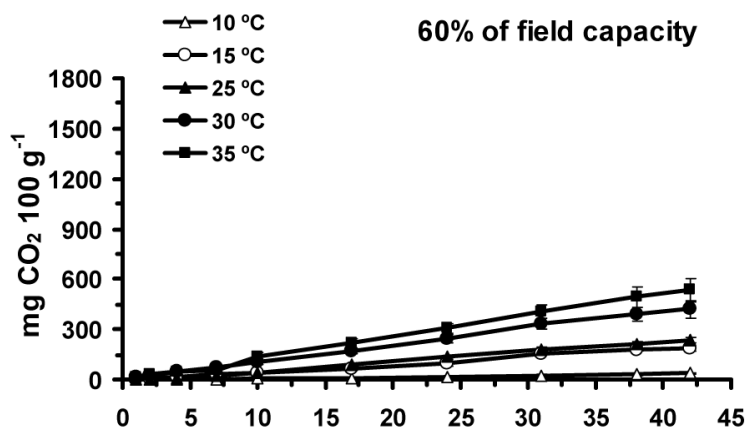

$80 \%$ of field capacity
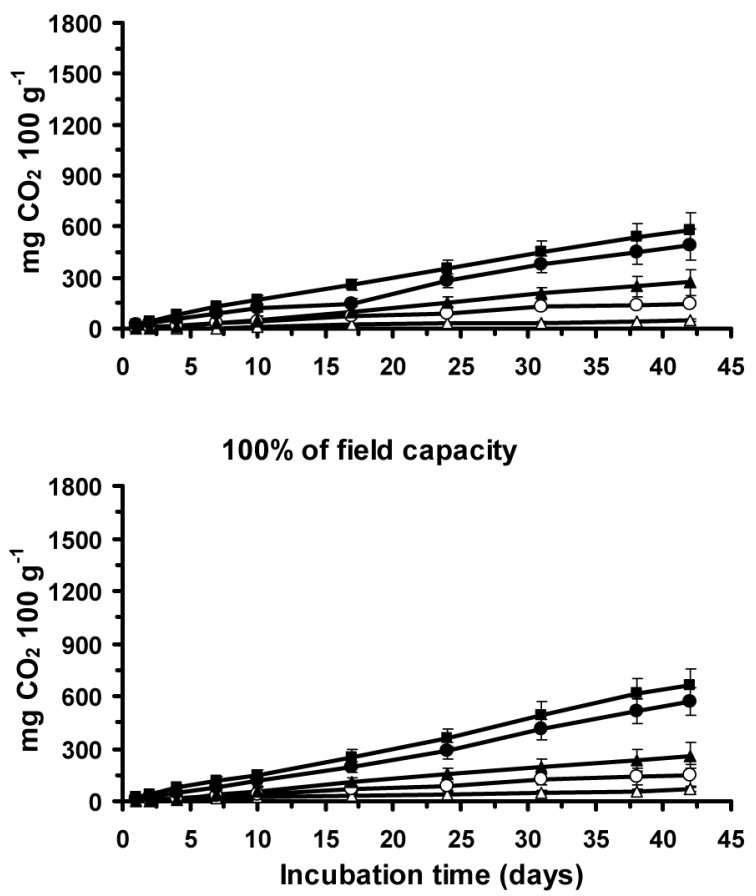

Figure 2. Cumulative carbon mineralization values $\left(\mathrm{mg} \mathrm{CO}_{z} 100 \mathrm{~g}^{-1}\right)$ measured at different temperatures and moisture contents over the incubation period (42 days) for the Cropped soil 
Table 2. Effect of temperature on soil respiration: parameters of equation 4 ( $\mathrm{b}$ and $Q_{10}$ ) obtained from the constant emission model, based on rates measured for equal amounts of carbon, and from the two-compartment model by using the $k_{2}$ values of the second compartment. For the same soil and different moisture level, the $Q_{10}$ values preceded by the same letter are not significantly different $(p<0.001)$; for the same moisture level and different soils, the $Q_{10}$ values followed by the same letter are not significantly different $(p<0.001)$.

\begin{tabular}{|c|c|c|c|c|c|c|c|}
\hline \multirow[t]{2}{*}{$\begin{array}{l}\text { Land-use } \\
\text { field capacity }\end{array}$} & \multirow[t]{2}{*}{ Moisture } & \multicolumn{3}{|c|}{ Constant emission model } & \multicolumn{3}{|c|}{$\begin{array}{l}\text { Two-compartment model(\% } \\
\text { (k } k_{2} \text { of second compartment) }\end{array}$} \\
\hline & & $r$ & $\mathrm{~b}$ & $Q_{10}$ & $r$ & $\mathrm{~b}$ & $Q_{10}$ \\
\hline \multirow[t]{4}{*}{ Forest } & $40 \%$ & $0.99^{* * *}$ & 0.1252 & $A 3.50 a$ & $0.98^{* * *}$ & 0.0419 & $A 1.52 a$ \\
\hline & $60 \%$ & $0.99^{* * *}$ & 0.1101 & $B 3.01 a$ & n.d. & n.d. & n.d. \\
\hline & $80 \%$ & $0.99^{* * *}$ & 0.1077 & $B C 2.93 a$ & $0.99^{* * *}$ & 0.0344 & $B 1.41 a$ \\
\hline & $100 \%$ & $0.99^{* * *}$ & 0.1034 & $C 2.81 a$ & $0.98^{* * *}$ & 0.0293 & $C 1.34 \mathrm{a}$ \\
\hline \multirow[t]{4}{*}{ Grassland } & $40 \%$ & $0.99^{* * *}$ & 0.1240 & $A 3.45 a$ & $0.99^{* * *}$ & 0.0507 & $A 1.66 b$ \\
\hline & $60 \%$ & $0.96^{* * *}$ & 0.0964 & $B 2.62 b$ & $0.97^{* * *}$ & 0.0231 & $B C 1.26 b$ \\
\hline & $80 \%$ & $0.98^{* * *}$ & 0.0899 & $C 2.46 b$ & $0.99^{* * *}$ & 0.0199 & $B 1.22 b$ \\
\hline & $100 \%$ & $0.98^{* * *}$ & 0.0871 & $C 2.39 b$ & $0.97^{* * *}$ & 0.0255 & $C 1.29 a$ \\
\hline \multirow[t]{3}{*}{ Cropland } & $60 \%$ & $0.94^{* * *}$ & 0.1056 & $A 2.88 a$ & $0.93^{* *}$ & 0.0385 & $A 1.47 b$ \\
\hline & $80 \%$ & $0.95^{* * *}$ & 0.1078 & $A 2.94 a$ & $0.92^{* *}$ & 0.0399 & $A 1.49 a$ \\
\hline & $100 \%$ & $0.95^{* * *}$ & 0.0992 & $B 2.70 a$ & $0.94^{* *}$ & 0.0358 & $A 1.43 b$ \\
\hline
\end{tabular}

${ }^{* * *} p<0.001 ;{ }^{* *} p<0.005$

\subsubsection{One- and two-compartment models}

The equation parameters of the one-compartment model (Equation 2) were inconsistent, as both the estimates of the potentially mineralizable carbon $\left(\mathrm{C}_{0}\right)$ and the values of the kinetic coefficient $\left(k_{o}\right)$ varied randomly for the different temperature and moisture conditions (data not shown).

This prevented valid conclusions being reached as regards the usefulness of the one-compartment model for determining either the potentially mineralizable carbon pool or the sensitivity of this to temperature.

The two-compartment model, which divides the soil organic matter into two compartments of different degrees of lability (labile and recalcitrant compartments), provided good fits (except for Grassland soil at $25{ }^{\circ} \mathrm{C}$ and for Cropland soil at 20 $\left.{ }^{\circ} \mathrm{C}\right)$. The labile pool was always extremely small (< $0.1 \%$ of the total soil carbon), suggesting that most of the organic matter mineralization is associated 
with transformation of a more recalcitrant pool. The kinetic coefficient for the recalcitrant compartment $\left(k_{2}\right)$ increased with temperature, with values of the same order for all three soils (data not shown). In all cases there was a clearly exponential relationship between temperature and $k_{2}$ values, which enabled estimation of the corresponding values of $Q_{10}$ (Table 2). Similarly to the results for the rate emission, the $Q_{10}$ values were generally lower in the Grassland soil than in the other soils, especially at the highest moisture contents, whereas the influence of moisture was only evident in the Forest soil, in which $Q_{10}$ decreased as the soil moisture increased. In the Grassland and Cropland soils, the values of $Q_{10}$ were very similar for each of the soils, for moisture contents higher than $60 \%$ (Table 2).

\subsection{Effect of moisture on $\mathrm{CO}_{2}$ emissions}

For the Cropland soil, none of the models used (equations 5, 6, 7 and 8) provided highly significant correlation coefficients $(r<0.83, p<0.02)$. For the Forest and Grassland soils, and for all temperatures, the model that best explained the relation between soil moisture and respiration was the complete parabolic model ( $r$ values between 0.95 and 0.99 , $p<0.001$ ), although the linear and semilogarithmic models also yielded high correlation coefficients ( $\mathrm{r}$ values between 0.91 and $0.98, p<0.01$ ).

In all three soils, and independently of the model considered, the values of the moisture coefficient $(\mathrm{qm})$ varied randomly with temperature for the emissions measured after incubation of the soils for 10 days. However, when the total period of incubation (42 days) was considered, the value of this coefficient increased with temperature. This was evident for Forest and Grassland soils in the linear and semilogarithmic models, and was observed for the Cropland soil only in the semilogarithmic model, because for this soil the linear model provided moisture coefficients that scarcely varied with temperature (data not shown).

\section{Discussion}

\subsection{Soil $\mathrm{CO}_{2}$ emission under the diverse incubation conditions}

The values obtained for the $\mathrm{CO}_{2}$ emitted from the three soils under different incubation conditions were similar to those previously reported for the A horizons of Galician soils under different types of use (Trasar-Cepeda et al., 2008). Although the total organic matter content and soil biochemical properties had important effects on mineralization, as the Grassland soil emitted significantly more $\mathrm{CO}_{2}$ than the other soils $(p<0.001)$, the main factors that determined soil organic carbon mineralization were temperature (fundamental factor) and moisture, as reported by other authors (Martens, 2000).

The maximum amount of $\mathrm{CO}_{2}$ emitted during the incubation $\left(\right.$ at $35{ }^{\circ} \mathrm{C}$ ) represented between 3.5 and $5.5 \%$ of the total carbon in the soil. These values are similar to those reported by Rey and Jarvis (2006) for a group of European forest soils, although the soils were incubated for a much longer period (270 days) than in the present study (42 days). Therefore, the rate of mineralization in Galician soils was higher than in the soils studied by Rey and Jarvis (2006), which suggests a greater abundance of readily mineralizable substrates in Galician soils. Although the high organic matter contents of Galician soils may suggest a low mineralization capacity, it has previously been observed that soil $\mathrm{CO}_{2}$ emissions respond rapidly to climate changes. This observation has been confirmed in field studies in which the soils were translocated to other sites with higher prevailing temperatures. In these studies it was observed that the soils lost a considerable amount of organic carbon within a short time, as a result of an increase in soil emission rate (Rey et al., 2007).

\subsection{Sensitivity of soil respiration to moisture}

The sensitivity of respiration to changes in soil moisture content is indicated by the first derivative of 
the function that related emission to soil moisture

Given that for all three soils the best fits between $\mathrm{CO}_{2}$ emission and soil moisture were provided by the semilogarithmic equation (as the values obtained for the Cropland soil did not fit the complete parabolic equation) and that the moisture coefficients obtained from this equation are positive, in all three soils the sensitivity of respiration to moisture $\left(q_{\mathrm{m}} / \mathrm{M}\right)$ decreased as soil moisture increased. Other authors (Xu et al., 2004; Misson et al., 2005, amongst others) have also found that drier soils are more sensitive to changes in moisture. However, the latter may not be accurate as the complete parabolic equation provided good fits for both the Forest and Grassland soils. Because of the structure of this equation, the sensitivity of respiration to moisture $\left(q_{\mathrm{m}}+2 q_{\mathrm{m}} \mathrm{M}\right)$ differed depending on the sign of the coefficients and on the moisture content Given that both the signs and the position of the vertex were different for each of the soils at the different temperatures and incubation times, it is difficult to provide a clear picture of the effect of moisture on respiration, as also indicated by other authors (Rodrigo et al., 1997).

\subsection{Sensitivity of soil respiration to temperature}

The response of all three soils to temperature was more consistent than the response to moisture, although in this case the data obtained from onecompartment model was rather inconsistent. With regard to the two-compartment model (Equation $3)$, the rate coefficients for the second compartment $\left(k_{2}\right)$ were clearly related to temperature through an exponential relationship, similarly to the rates of emission obtained for the same amount of emitted carbon (constant emission model, equation 1), and thus in both cases the corresponding $Q_{10}$ values were obtained from equation 2 (Table 2). The $Q_{10}$ values obtained from both of these models for all soils and moisture conditions were closely related $(r=0.88$, $p<0.001$ ), although the values obtained from $p<0.001$ ), although the values obtained from the two-compartment model were significantly lower $(p<0.001)$ than those obtained from the constant emission model (Figure 3), considering each soil separately (mean values for all moisture levels), as well as each moisture level (considering mean values for the three soils) or the mean value for all situations (Table 3).

The mean $Q_{10}$ value for all situations from the constant emission model was $2.87 \pm 0.37$, whereas from the second compartment was $1.41 \pm 0.13$ (Table 3 ). The former value is very close to the overall mean values of 2.3 reported by Lenton and Huntingford (2003), whereas the latter value is closer to the overall mean value of 1.3 reported by Ise and Moorcroft (2006).

In other words, the overall organic matter mineralization in the three soils (reflected by the rates of emission obtained in equation 1 , constant emission model) is more sensitive to temperature than the recalcitrant organic matter mineralization (represented by the rates of mineralization of the second compartment). This difference in mean $Q_{10}$ values may be explained by considering that the most labile fraction of the soil organic matter (and which obviously is not considered in the calculation of the mineralization coefficients in the second compartment) is more sensitive to temperature than the recalcitrant organic matter. This may reflect a different degree of sensitivity of the recalcitrant organic matter than indicated by many authors (Leifeld and Fuhrer, 2005; Fierer et al., 2006; Cross and Grace, 2006). However, the random behaviour shown by the labile fraction in response to temperature suggests another possible explanation for the differences in the $Q_{10}$ values. It therefore appears more likely that rewetting the soils to produce the range of moisture contents used in the incubation would have generated an intense flush of $\mathrm{CO}_{2}$, which would be higher at higher incubation temperatures. This high initial rate of mineralization may be responsible for the highest values of $Q_{10}$ obtained with the constant emission model. When this 
initial effect (usually after 24-72 hours) is buffered (Chen et al., 2010), soil respiration stabilizes (i.e. it reaches a level that can be considered typical, and not influenced by the initial conditions of the incubation), so that the temperature sensitivity can be calculated more accurately. This is reflected by the $Q_{10}$ values in the second compartment, in which the initial mineralization is not considered In fact, when the $Q_{10}$ values for the different soils and moisture contents were estimated from the data on net $\mathrm{CO}_{2}$ emissions, a decrease in the sensitivity to temperature throughout the incubation period was observed in all cases (Guntiñas, unpublished data). Although this contrasts with the findings of Hartley and Ineson (2008), who reported an increase in $Q_{10}$ as the incubation time increased, the gradual decrease in this parameter throughout the incubation period reflects the end of the flush that was generated by rewetting the soil. It therefore appears that in estimating $Q_{10}$, the first moments of the incubation should not be taken into account because of the possible distortion that may be generated in calculating the parameter. On the other hand, the fact that the $Q_{10}$ values estimated from the values obtained for the second compartment were very similar for the different soils under study (Table 3) suggests that the type of land use has not created any appreciable change in the sensitivity of the organic matter to temperature, even though the contents of readily mineralizable organic matter were different in three soils under study, as reflected by the amounts of extractable carbohydrates or the \% of mineralizable organic matter extracted with permanganate (Table 1). The similar behaviour of the organic matter in soils under different types of land-use is not consistent with our starting hypothesis, i.e., that as organic matter will differ in soils under different types of use, the mineralization will also differ. However, the fact that the soils under different types of use behave similarly may facilitate evaluation of the impact of climate change on $\mathrm{CO}_{2}$ emissions, as for a given area it would be independent of the soil use.

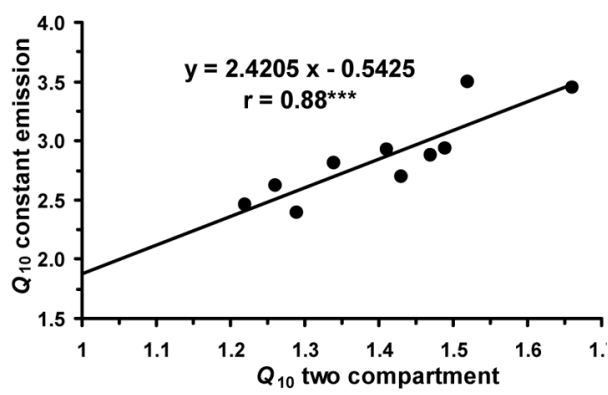

Figure 3. Relationship between the values of $Q_{10}$ estimated by the two-compartment model and the values of $Q_{10}$ estimated by considering the rates of mineralization for the same total amounts emitted, constant emission model $\left({ }^{* * *} p<0.001\right)$

\subsection{Effects of the interaction between moisture and temperature on soil respiration}

Independently of the above-mentioned increase in soil respiration at the start of the incubation period, the $Q_{10}$ values estimated by both of the models (constant emission and second compartment of the two-compartment model) decreased as the soil moisture increased. In other words, although the net mineralization was most intense at higher levels of soil moisture, soil respiration was less sensitive to temperature at field capacity than under drier conditions (Table 3 ). The decrease in sensitivity was more evident for the values of $Q_{10}$ obtained from the constant emission model than for the values obtained from the two compartment model (for which $Q_{10}$ remains almost constant for moisture contents higher than $60 \%$ ). Contrary to what we expected on the basis of our hypothesis, the results of the present study indicate that the temperature sensitivity data obtained in the laboratory under conditions of field capacity may underestimate the real effect of variations in temperature on the emission of $\mathrm{CO}_{2}$ in soils under field conditions. Craine and Gelderman (2011) have 
reported similar findings, and concluded that more research is required to clarify why the optimal soil moisture content for organic matter decomposition differs in different soils. Nonetheless, it is clear that variations in soil moisture alter the temperature sensitivity of the decomposition process, and may either amplify or reduce the direct effects of temperature on soil respiration.

Table 3. Mean values of $Q_{10}$ obtained from the constant emission model and for the two-compartment models grouped by land use and soil moisture content. Within each row, the $Q_{10}$ values followed by the same lower case letter are not significantly different $(p<0.001)$. For each land-use and moisture level, $Q_{10}$ values preceded by the same capital letter are not significantly different $(p<0.001)$.

\begin{tabular}{lcc}
\hline & $\begin{array}{c}\text { Constant } \\
\text { emission model }\end{array}$ & $\begin{array}{c}\text { Two-compartment } \\
\text { model }^{\mathrm{a}}\end{array}$ \\
\hline $\begin{array}{l}\text { Land-use } \\
\text { Forest }\end{array}$ & $A 3.06 \pm 0.30 \mathrm{a}$ & $A 1.42 \pm 0.09 \mathrm{~b}$ \\
Grassland & $A 2.73 \pm 0.49 \mathrm{a}$ & $A 1.36 \pm 0.20 \mathrm{~b}$ \\
Cropland & $A 2.84 \pm 0.12 \mathrm{a}$ & $A 1.46 \pm 0.03 \mathrm{~b}$
\end{tabular}

$\begin{array}{lll}\text { Moisture levels }^{c} & & \\ 40 \% & A 3.48 \pm 0.04 a & A 1.59 \pm 0.10 b \\ 60 \% & B 2.84 \pm 0.20 a & B 1.36 \pm 0.15 b \\ 80 \% & B 2.78 \pm 0.27 a & B 1.35 \pm 0.08 b\end{array}$

$\begin{array}{lrl}\text { All cases } & 2.87 \pm 0.37 a & 1.41 \pm 0.13 b\end{array}$

${ }^{a}$ values for the second compartment; ${ }^{\mathrm{b}}$ for each soil, mean value obtained for all moisture levels; ${ }^{\mathrm{c}}$ for each moisture level, mean value obtained for the three soils

\section{Conclusions}

The effect of the quality of the organic matter on the response to changes in moisture and temperature was not clear, as it varied depending on the model considered and was not closely related to any of the chemical parameters of the organic matter.

Moreover, the results of the present study indicate that in estimating the sensitivity of soil respiration to temperature and moisture in incubation experiments, the data obtained during the first moments of the incubation should be disregarded, as long as the soil has not been preincubated. Furthermore, as the sensitivity of respiration to temperature is higher at low soil moisture contents, it appears that for studies on temperature sensitivity (using controlled conditions in similar soils), incubation experiments should not be carried out under soil moisture 
conditions close to field capacity, although this is usually recommended. Therefore, it is clear that any model for predicting $\mathrm{CO}_{2}$ emissions from soils must consider the effects of both temperature and moisture, as well as the combined effects of both variables.

The constant emission model showed the Grassland soil to be the least sensitive to changes in temperature and moisture, whereas the $Q_{10}$ model showed that the soils under all three types of use responded similarly, with the Cropland soil being the least sensitive. In light of these differences, and considering that the data shown were obtained for only three soils (one for each type of use), further work with more soils developed under different conditions is required to clarify whether the organic matter of soils under different types of uses respond in similar or different ways to climate change. This would provide optimal useful tool for planning the best type of soil use to minimize the effect of climate change on the emission of $\mathrm{CO}_{2}$ from soil.

\section{Acknowledgements}

This research was financially supported by the Spanish and by the Spanish Ministerio de Ciencia e Innovación. (Project No CGL2008-01992/BTE).

\section{References}

Andrén, O., Paustian, K. 1987. Barley straw decomposition in the field: a comparison of models. Ecology. 68, 1190-1200.

Bowden, R.D., Newkirk, K.M., Rullo, G.M. 1998. Carbon dioxide and methane fluxes by a forest soil under laboratory-controlled moisture and temperature conditions. Soil Biol. Biochem. 30, 1591-1597.
Ceccanti, B., Masciandaro, G., García, C. 1993. Anaerobic digestion of straw and piggery waste water: I. Preliminary studies. Agrochimica XXXVII, 147-156.

Chen, X., Tang, J., Jiang, L., Li, B., Chen, J., Fang, Ch. 2010. Evaluating the impacts of incubation procedures on estimated $Q_{10}$ values of soil respiration. Soil Biol. Biochem. 42, 22822288.

Cox, P.M., Betts, R.A., Jones, C.D., Spall, S.A., Totterdell, I.J. 2000. Acceleration of global warming due to carbon-cycle feedbacks in a coupled climate model. Nature 408, 184-187.

Craine, J.M., Gelderman, T.M. 2011. Soil moisture controls on temperature sensitivity of soil organic carbon decomposition for a mesic grassland. Soil Biol. Biochem. 43, 455-457.

Cross, A., Grace, J. 2010. The effect of warming on the $\mathrm{CO} 2$ emissions of fresh and old organic soil from under a Sitka spruce plantation. Geoderma 157, 26-132.

Curiel-Yuste, I., Baldocchi, D.D., Gershenson, A., Goldstein, A. 2007. Microbial soil respiration and its dependency on carbon inputs, soil temperature and moisture. Global Change Biol. 13, 1-18.

Dalias, P., Anderson, J.M., Bottner, P., Coûteaux, M.M. 2001. Long-term effects of temperature on carbon mineralisation processes. Soil Biol. Biochem. 33, 1049-1057.

Davidson, E.A., Janssens, I., Luo, Y. 2006. On the variability of respiration in terrestrial ecosystems: moving beyond $Q_{10}$. Global Change Biol. 12, 154-164.

de Castro, M.N., Martin-Vide, J., Alonso, S. 2005. El clima de España: pasado, presente y escenarios de clima para el siglo XXI. In: Oficina del Cambio Climático (eds.). Impactos en España por efecto 
del cambio climático. Oficina del Cambio Climático, Madrid, pp: 1-64.

Fang, C., Smith, P., Moncrieff, J.B., Smith, J.U. 2005. Similar response of labile and resistant soil organic matter pools to changes in temperature. Nature. 433, 57-59.

Fierer, N., Colman, B.P., Schimel, J.P., Jackson, R.B. 2006. Predicting the temperature dependence of microbial respiration in soil: A continental-scale analysis. Global Biogeochem. Cy. 20:GB3026, DOI 10.1029/2005GB002644.

Foereid, B. 2007. Estimating soil feedbacks to climate change. In: R. Jandl, M. Olsson (eds.). Greenhouse-gas budget of soils under changing climate and land use (BurnOut). COST Action 639, Vienna, pp: 23-32.

García, A.I., Pérez, M. 2001. Análise e evolución da aplicación en Galicia do programa de axudas a forestación de terras agrarias (Règ. CEE 2080/92). Rev. Gal. Econ. 10, 151-176.

Giardina, C.P., Ryan, M.G. 2000. Evidence that decomposition rates of organic carbon in mineral soil do not vary with temperature. Nature. 404, 858-861.

Guitián, F., Carballas, T. 1976. Técnicas de análisis de suelos. Editorial Pico Sacro, Santiago de Compostela, 288 pp.

Hartley, I.P., Ineson, Ph. 2008. Substrate quality and the temperature sensitivity of soil organic matter decomposition. Soil Biol. Biochem. 40, 15671574.

Heidmann, T., Christensen, B.T., Olesen, S.E. 2002. Changes in soil $\mathrm{C}$ and $\mathrm{N}$ content in differing cropping systems and soil types. In: S.O. Petersen, J.E. Olesen (eds.). Greenhouse Gas Inventories for Agriculture in the Nordic Countries. Ministry of Food, Agriculture and Fisheries, Danish of Agricultural Sciences, report 81, Foulum, Denmark, pp: 77-86.

IPCC WG1, Climate Change 2007. The Physical Science Basis. Cambridge University Press, Cambridge, 996 pp.

Ise, T., Moorcroft, P.R., 2006. The global-scale temperature and moisture dependencies of soil organic carbon decomposition: an analysis using a mechanistic decomposition model. Biogeochemistry. 80, 241-261.

ISSS Working Group R.B. 1998. World Reference Base for Soil Resources: Introduction, International Society of Soil Science, International Soil Reference and Information Centre and Food and Agriculture Organization of the United Nations. Acco, Leuven, $78 \mathrm{pp}$.

Kirkby, K.J., Smart, S.M., Black, H.I.J., Bunce, R.G.H., Corney, P.M., Smithers, R.J. 2005. Long term ecological change in British woodland (19712001). English Nature Research Report 653, English Nature. Peterborough, 139 pp.

Kirschbaum, M.U.F. 2000. Will changes in soil organic carbon act as a positive or negative feedback on global warming?. Biogeochemistry. 48, 21-51.

Leifeld, J., Fuhrer, J. 2005. The temperature response of $\mathrm{CO}_{2}$ production from bulk soils and soil fractions is related to soil organic matter quality. Biogeochemistry. 75, 433-453.

Lenton, T.M., Huntingford, C. 2003. Global terrestrial carbon storage and uncertainties in its temperature sensitivity examined with a simple model. Global Change Biol. 9, 1333-1352.

Liski, J., Palosuo, T., Peltoniemi, M., Sievänen, R. 2005. Carbon and decomposition model Yasso for forest soils. Ecol. Model. 189, 168-182. 
Mager, D.M. 2010. Carbohydrates in cyanobacterial soil crusts as a source of carbon in the southwest Kalahari, Botswana. Soil Biol. Biochem. 42, 313-318.

Martens, D.A. 2000. Plant residue biochemistry regulates soil carbon cycling and carbon sequestration. Soil Biol. Biochem. 32, 361-369.

Miralles, I., Ortega, R., Almendros, G., SánchezMarañón, M., Soriano, M. 2009. Soil quality and organic carbon ratios in mountain agroecosystems of South-east Spain. Geoderma. 150, 120-128.

Misson, L., Tang, J.W:, Xu, M., McKay, M., Goldstein, A. 2005. Influences of recovery from clear-cut, climate variability, and thinning on the carbon balance of a young ponderosa pine plantation. Agr. Forest. Meteorol. 130, 207-222.

Rey, A., Jarvis, P. 2006. Modelling the effect of temperature on carbon mineralization rates across a network of European forest sites (FORCAST). Global Change Biol. 12, 1894-1908.

Rey, M., Guntiñas., E., Gil-Sotres, F., Leirós, M.C., Trasar-Cepeda, C. 2007. Translocation of soils to simulate climate change: $\mathrm{CO}_{2}$ emissions and modifications to soil organic matter. Eur. J. Soil Sci. 58, 1233-1243.

Rodrigo, A., Recous, S., Neel, C., Mary, B. 1997. Modelling temperature and moisture effects on $\mathrm{C}-\mathrm{N}$ transformations in soils: comparison of nine models. Ecol. Model. 102, 325-339.
Sleutel, S., De Neve, S., Hofman, G. 2003. Estimates of carbon stock changes in Belgian cropland. Soil Use Manage. 19, 166-171.

Smith, P., Fang, C., Dawson, J.J.C., Moncrieff, J.B. 2008. Impact of global warming on soil organic carbon. Adv. Agron. 97, 1-43.

Stanford, G., Smith, S.J. 1972. Nitrogen mineralization potential of soils. Soil Sci. Soc. Am. Proc. 36, 465-472.

Tirol-Padre, A., Ladha, J.K. 2004. Assessing the reliability of permanganate-oxidizable carbon as an index of soil labile carbon. Soil Sci. Soc. Am. J. 68, 969-978.

Trasar-Cepeda, C., Leirós, M.C., Seoane, S., GilSotres, F. 2008. Biochemical properties of soils under crop rotation. Appl. Soil Ecol. 39, 133143.

Xu, L.K., Baldocchi, D.D., Tang, J.W. 2004. How soil moisture, rain pulses, and growth alter the response of ecosystem respiration to temperature. Global Biogeochem. Cy. 18:GB4002, DOI 10.1029/2004GB002281. 